\title{
The chalk drums from Folkton and Lavant: Measuring devices from the time of Stonehenge
}

DOI:

10.1080/17498430.2018.1555927

\section{Document Version}

Accepted author manuscript

Link to publication record in Manchester Research Explorer

\section{Citation for published version (APA):}

Teather, A., Chamberlain, A., \& Parker Pearson, M. (2018). The chalk drums from Folkton and Lavant: Measuring devices from the time of Stonehenge. British Journal for the History of Mathematics, 34(1), 1-11.

https://doi.org/10.1080/17498430.2018.1555927

\section{Published in:}

British Journal for the History of Mathematics

\section{Citing this paper}

Please note that where the full-text provided on Manchester Research Explorer is the Author Accepted Manuscript or Proof version this may differ from the final Published version. If citing, it is advised that you check and use the publisher's definitive version.

\section{General rights}

Copyright and moral rights for the publications made accessible in the Research Explorer are retained by the authors and/or other copyright owners and it is a condition of accessing publications that users recognise and abide by the legal requirements associated with these rights.

\section{Takedown policy}

If you believe that this document breaches copyright please refer to the University of Manchester's Takedown Procedures [http://man.ac.uk/04Y6Bo] or contact uml.scholarlycommunications@manchester.ac.uk providing relevant details, so we can investigate your claim.

\section{OPEN ACCESS}




\section{Journal of the British Society for the History of Mathematics The Chalk Drums from Folkton and Lavant: Measuring Devices from the Time of Stonehenge --Manuscript Draft--}

\begin{tabular}{|l|l|}
\hline Full Title: & $\begin{array}{l}\text { The Chalk Drums from Folkton and Lavant: Measuring Devices from the Time of } \\
\text { Stonehenge }\end{array}$ \\
\hline Manuscript Number: & TBSH-2018-0010R1 \\
\hline Article Type: & Original Article \\
\hline Keywords: & Neolithic, measures, construction, chalk, monuments \\
\hline Abstract: & $\begin{array}{l}\text { Investigating knowledge of mathematics and the use of standard units of measurement } \\
\text { in prehistoric societies is a difficult task. For the British Neolithic period (4000-2500 BC) } \\
\text { attempts to refine our understanding of mathematical knowledge for this period have } \\
\text { been largely unsuccessful until now. Following recent research, we propose that there } \\
\text { is a direct link between the design of the monument of Stonehenge and the chalk } \\
\text { artefacts known as the Folkton and Lavant Drums, through the Drums representing } \\
\text { measurement standards that were essential for accurate and reproducible monument } \\
\text { construction. This has important implications for the future analyses of artefacts and } \\
\text { monuments for this period. }\end{array}$ \\
\hline Order of Authors: & \begin{tabular}{l} 
Anne Teather \\
\hline Andrew Chamberlain
\end{tabular} \\
\hline Mike Parker Pearson \\
\hline
\end{tabular}

Response to Reviewers:

We very much appreciate the comments of our two reviewers and respond as follows.

Reviewer 1

We are pleased that this reviewer fully comprehends the direction of our paper and can clearly articulate our hypothesis for the chalk drums representing measurement standards. The issue of prehistoric measurement standards has a contentious history in Neolithic studies, and we have tried to demonstrate a careful and robust approach to the evidence, as this reviewer acknowledges.

As suggested by the reviewer, we have undertaken some additional research that indicates that some other monuments in Britain and Ireland may have been constructed using this system, in particular those connected with the Grooved Ware phenomenon, citing Bradley. We concur that the use of standardised measurements very likely indicates a form of social power, although we do not wish to extend our inferences further by suggesting that this may indicate a type of special grave for the children as 'measurers'. Unfortunately, this kind of distinction can tend to restrict rather than expand other interpretations and with no other parallels we feel it may be unhelpful.

\section{Reviewer 2}

The reviewer has highlighted the rarity of the artefacts and suggested that we include a broader discussion of ideas of measurement in the Neolithic. Accordingly we have added a further discussion of the problems with the Megalithic Yard proposed by Thom, and have cited the work of Ruggles and MacKie, in addition to examining other early henge sites. Of these we have been able to suggest that this measurement may have been utilised in constructing highly regular circles at the Ring of Brodgar, Scotland and at Newgrange, Ireland, both sites dating to a similar period as the construction of the Stonehenge ditch and Aubrey holes c. 3000BC.

This reviewer also drew attention to the measurement of the Folkton Drums on grounds of precision. It is, contrary to the reviewer's comment, exceptionally difficult to obtain access to display artefacts at the British Museum as this has to be completed in non-opening times. After we completed an examination of published sources, we noted that there is some variability in the measurement of the Folkton Drums, with errors common (e.g Jones et al. 2016 where an incorrect scale has been used; indeed the measurements on the British Museum's own website were incorrect until we pointed 
this out to them). The drawings and measurements completed by Longworth and by Greenwell (the original excavator) appear highly consistent and we have used these published sources. Minor variations in the size of the drums are probably due to taking measurements in different places on the circular artefacts, or minor measurement error, and completing our own does not appear necessary for this purpose. In prehistory we should not expect a standard of measurement applied to a decimalised standard, particularly in the case of potential skeuomorphs as we argue here. The important point we have raised is of the connection between the dimensions of the drums and the unit of measurement underlying the construction of large monuments.

There is also concern expressed by the reviewer that the skeuomorphic nature of the drums is too speculative. We have added a reference to show that this behaviour in the Neolithic with chalk has been suggested previously. It is an interpretive step although it seems founded more in inference than the reviewer suggests. Archaeologists have found chalk axes that clearly represent stone axes, so if the original measurement standard was made of stone we would probably have found surviving examples; the fact we do not suggests any measure in use may have been made of a durable but perishable material such as wood. Hence, we have added a short reference to Must Farm, a Late Bronze Age archaeological site in East Anglia that has produced a wealth of surviving wooden artefacts (including a wooden box) and also to a Neolithic site on the continent with preserved wood, in support of our inference that such wooden artefacts may also have been present during the Neolithic. 


\title{
The Chalk Drums from Folkton and Lavant: Measuring Devices from the Time of Stonehenge
}

\begin{abstract}
Investigating knowledge of mathematics and the use of standard units of measurement in prehistoric societies is a difficult task. For the British Neolithic period (4000-2500 BC) attempts to refine our understanding of mathematical knowledge for this period have been largely unsuccessful until now. Following recent research, we propose that there is a direct link between the design of the monument of Stonehenge and the chalk artefacts known as the Folkton and Lavant Drums, in which the Drums represent measurement standards that were essential for accurate and reproducible monument construction. This has important implications for the future analyses of artefacts and monuments for this period.
\end{abstract}

\section{Introduction}

Within studies of the British Neolithic, material culture and monument forms are commonly approached in different ways. Material culture is largely examined through the form, function and decoration of artefacts such as stone tools and pottery vessels (Hurcombe 2007, 59), while monuments (i.e. large-scale earthworks and structures built of timber and stone) are studied through elements of their construction, and evidence for their inferred use (Cummings 2008). This conventional approach inadvertently poses an interpretive separation, whereby items of material culture are sometimes conceived as being supplementary to British Neolithic monumental activity, and simply form an incidental part of the archaeological record.

Yet, particularly unusual monuments and rare, decorated artefacts, are treated differently. Non-utilitarian artefacts such as carved stone balls or the highly decorated chalk Folkton Drums (Figure 1), and exceptional monument complexes such as Stonehenge, invite speculation concerning their wider purpose and the reasons behind the intricacy of their design. Robb $(2015,639)$ suggested that remarkable, unusual or enigmatic objects such as the Folkton Drums can be classified in a group of their own as 'bodies of art generated by highly local recombinations or exaggerations of generally known elements, which include only one 
or a few unusual objects'. This view perpetuates the impression that, while there were utilitarian and stylistic principles underlying the construction of some artefacts, certain unusual objects fall outside normative expectations and must remain inaccessible to archaeological interpretation.

\section{[FIGURE 1 HERE]}

At times, focus has been given to mathematical interpretations of prehistoric monuments and material culture, although not always by archaeologists. Recently, arguments that carved stone balls may have been representative of an early understanding of the geometry underlying the form of the Platonic Solids were countered by Lloyd (2012). He argued that their complexity of design emerges from the practical solution to the problem of distancing varying numbers of protrusions evenly and symmetrically across the surface of the spherical ball. Here we propose a link between an artefact category - chalk drums - and a monument category - the complex henge and stone circle of Stonehenge - that superficially share few attributes other than their circular symmetry and the chalk rock that forms their substrate.

Stonehenge is a highly complex Neolithic ceremonial monument situated on chalk downland in Wiltshire in southern Britain. The monument consists of concentric circular arrangements of earthworks, pits, postholes and stone settings arranged symmetrically around a common central point. There is consensus that the orientation of the monument and its constituent parts, at least in its later phases of use, was related to the observation of celestial phenomena including solar and lunar horizon positions (Ruggles 1999). However, there has been much debate over whether this monument in particular incorporated a standardised linear measure of distance (Chippindale 1983). The symmetry and astronomical alignments of prehistoric monuments are, to a certain extent, scale-independent and therefore do not require the existence of a fixed standard of measurement; nonetheless, if such a standard or standards did exist there would be important implications for our understanding of prehistoric technology and society (MacKie 1977).

A study of the diameters of the various circular structures at Stonehenge has suggested that these constructional elements were laid out from a common centre using radii in regular multiples of a standard unit of $0.3219 \mathrm{~m}$, referred to as the 'long foot' (Chamberlain and Parker Pearson 2007, 170). A circular setting of timber posts at the nearby Late Neolithic site of Durrington Walls provided additional supporting evidence for the use of the long-foot unit (Chamberlain and Parker Pearson 2007, 171). However, until now there has been limited 
evidence for the use of this unit of measurement elsewhere in Neolithic Britain. Here we are able to demonstrate an unexpected link between the design of Stonehenge and the dimensions of the chalk drums from Folkton in North Yorkshire and Lavant in West Sussex that incorporates these very different artefacts into a common mathematical framework.

\section{Measuring and building monuments}

We identify circular monuments beginning in the British Late Neolithic period c. 3000 BC. These are manifested as two types: bank-and-ditch earthen enclosures with one or more entrances known as henges; and circular settings constructed of individual upright timbers or stones, sometimes as single circuits but in some instances as multiple concentric circles. Although the timber settings (most likely tree trunks) degraded millennia ago, the pits that received the posts remain in the subsoil and we can accurately reconstruct surface layout patterns from this evidence. While many of these monuments are difficult to date precisely, they appear to have been built and reworked at various moments during the third millennium BC.

The regularities in the plans of circular earthworks and timber and stone settings suggests that, at least at the level of individual monuments, a system of measurement was used to set out the positions of banks, ditches and orthostats. However, the spatial arrangements of the principal elements of these monuments could have been determined by regular pacing (Porteous 1973) and the monumental architecture does not, of itself, necessitate the existence of a fixed unit of measurement in the British Neolithic.

Direct evidence for the existence of standard measurement units could be gained from rulers or measuring rods, and later prehistoric examples of these have been found in Denmark (Glob 1974), Germany (Sievers 2002) and Ireland (Raftery 1986). However, measuring devices are not thought to have survived from the British Neolithic or indeed from any other period of British prehistory.

An indirect procedure for discerning units of measurement is to look for regularities in the dimensions of prehistoric monuments, in the expectation that peaks in the distributions of lengths, breadths and diameters, and perhaps circumferences, will cluster at multiples of a fundamental unit or 'quantum'. This method of inference was applied by Alexander Thom to selected measurements from surveys of British prehistoric stone circles and stone rows 
(Thom 1955; 1967), but the resulting quantum of the Megalithic Yard (equivalent to $0.8291 \mathrm{~m}$ ) failed to gain widespread acceptance amongst prehistorians and statisticians.

Rigorous quantitative treatment of Thom's measurements by several independent researchers found that the evidence for the use of a Megalithic Yard reached a satisfactory level of statistical significance only amongst a restricted sample of Scottish stone circles (Kendall 1974; Freeman 1976; Barnatt and Moir, 1984; Baxter 2003).

In the case of Stonehenge, Thom et al. (1974) fitted circles with circumferences of integer multiples of Megalithic Rods (a unit equal to 2.5 Megalithic Yards) to some of the circular components of the monument. However, Thom accepted a broad tolerance of $+/$ - one quarter unit when determining diameters and circumferences of stone circles in his Megalithic units (Thom 1967, 47; MacKie 1977, 43) and it is difficult to avoid the conclusion that the dimensions identified by Thom at Stonehenge may be coincidental.

Chamberlain and Parker Pearson (2007) showed through trial calculations that the measured diameters of Phase 1 of Stonehenge (the earthwork phase consisting of the Ditch, Bank and Aubrey Hole circuits) conform to a single standard measure that differs from the units identified by Alexander Thom. According to Chamberlain and Parker Pearson (2007), the diameters of these components of Stonehenge can be approximated very closely by a series of concentric circles with modular diameters computed in multiples of 30 from a base unit of a 'long' foot, equal to 1.056 modern or statute feet or to 0.3219 metres.

Furthermore, the spacing between some of the megalithic components of the monument including the distances between adjacent Aubrey Holes and between the segments of the Sarsen Circle - show repeated use of a dimension corresponding to 10 times and 15 times the same long-foot unit (see Figure 2). An appropriate independent test of the concept of a base unit measurement at Stonehenge was provided by the layout of timber post settings at Durrington Walls, a contemporary Neolithic henge monument which is located $3 \mathrm{~km}$ to the northeast of Stonehenge. Excavations at Durrington Walls in 1966-1968 (Wainwright with Longworth 1971) revealed just over two thirds of the ground plan of a concentric arrangement of postholes, designated the Southern Circle (Figure 3). The five circuits of Phase 2A posts together with the outermost Phase $2 \mathrm{~B}$ circuit of posts at this monument have diameters of 30, 50, 70, 90, 110 and 120 long feet. 


\section{Regularity in the dimensions of the Folkton and Lavant Drums}

The Folkton Drums were excavated in 1889 by Canon Greenwell from a barrow near the village of Folkton in East Yorkshire (Greenwell 1890). Morphologically, the drums are cylindrical artefacts with inscribed surface decoration and an inset-raised top (Kinnes and Longworth 1985, 115-18). The three objects, carved in solid chalk, are of varying size and were associated with the burial of a child, and are thought to date to the late Neolithic (3000$2500 \mathrm{BC})$ or Beaker period (2500-1800 BC).

The inscribed motifs carved on the tops and sides of the Folkton Drums have been argued to be part of a Neolithic design tradition also found on Grooved Ware pottery, passage grave art and other forms of material culture (Wainwright with Longworth 1971, 246; Thomas 1996, 156). Subsequent analysis has tended to emphasise the uniqueness of the Folkton Drums (Longworth 1999, 87) or their ambiguous and improvisational nature (Jones 2012, 179). However, their purposeful manufacture and likely curation has been demonstrated by recent studies of their decoration using Reflective Transformation Imaging (RTI), which have shown evidence for repeated erasure and re-working of some of the decorative elements (Jones et al. 2015, 1090). Furthermore, the finding of an additional chalk drum at Lavant in West Sussex suggests that the apparent uniqueness of the Folkton artefacts may have been over-emphasised (Kenny and Teather 2016).

The worked chalk drums from Folkton and Lavant show a regularity of form that suggests manufacture to a common template. The maximum diameters of the Folkton drums have been documented by Kinnes and Longworth (1985) as 146, 125 and 104mm, corresponding closely to the original measurements by Greenwell (1890) of 146, 127 and 102mm (converted from Greenwell's original measurements which were reported to the nearest $1 / 8$ th inch). The measured diameters given here of 145, 126 and 103mm were taken independently from scaled drawings published in Kinnes and Longworth (1985) and agree to within 1mm with the previously published measurements.

The Lavant drum was excavated in 1993 from a pit containing Neolithic material and has dimensions that are intermediate between those of the smallest (Folkton III) and the middle (Folkton II) drums (see Figure 4 and Table 1). The Lavant drum may have been relatively unfinished compared to the Folkton drums, as it has very limited incised decoration compared 
to the Folkton examples. Smoothing of the base and smoothing and/or decoration of the 'lid' to complete the manufacture of the artefact would have reduced the height of the Lavant drum by a few millimetres, giving it a height/diameter ratio closer to that of the Folkton drums.

\section{[FIGURE 4 HERE]}

It is apparent that there is not an equal spacing in size between these four drums. However, we have noted (see Table 1) that the smallest drum (Folkton III) has a circumference that is very close (within 1\% error) of the length of the long foot (equivalent to 1.056 statute feet) that Chamberlain and Parker Pearson (2007) postulated as the basis for the construction of Stonehenge and the Southern Circle at Durrington Walls.

The larger drums (Lavant, Folkton II and Folkton I) have circumferences that are close to integer subdivisions of 10 long feet. Thus, a length of 10 long feet can be marked out by 10 rotations of Folkton III, 9 rotations of Lavant, 8 rotations of Folkton II and 7 rotations of Folkton I. The diameters, and hence the circumferences, of these four drums therefore form a mathematical harmonic sequence, because they fall into a sequence of the reciprocals $1 / 10,1 / 9$, $1 / 8$ and $1 / 7$ and so form a graduated set. We consider this sizing to have been deliberately incorporated into their design in order to allow the use of the drums as standards of linear measurement.

\section{[TABLE 1 HERE]}

Each of the drums may have served as a standard for measuring a cord of a length of 10 long feet, requiring only that the length be determined by the requisite number of rotations of the particular drum. Furthermore, the set of drums together could be used as required in order to subdivide a measure of 10 long feet into either 10, 9, 8 or 7 equal units, a property that may have been useful for certain constructional projects where fractions of the unit measure were required.

Chamberlain and Parker Pearson $(2007,173)$ commented that their findings of evidence for the existence of the long foot were preliminary and required corroboration. That the Folkton and Lavant Drums appear to confirm this measure of a long foot provides further evidence that there was a standard measure in the British Neolithic and that this unit may have been 
used at least throughout the chalklands of Britain rather than being confined to the heartland of Neolithic Wessex.

\section{Discussion}

The regularity of the dimensions of the chalk drums and their close relation to the long foot unit of measurement in use at Stonehenge and the Southern Circle at Durrington Walls indicate that these measurements were standardised and could have been used in relation to monument construction, potentially across a wide area of Neolithic Britain. The Folkton Drums originate from an archaeological site in Yorkshire and are made of chalk that was sourced locally from that area (Middleton et al. 2004). While no radiocarbon dates are available yet for the contexts within which any of the Drums were found, they are likely to date to the third millennium BC, broadly contemporary with the building of Stonehenge and the Southern Circle at Durrington Walls. The chalk drums from Folkton are obviously not geographically close to Stonehenge, although the find location of the Lavant Drum is within 60 miles of Stonehenge.

Although many Neolithic circular monuments have been recorded on the chalklands of Britain there are few that have been excavated in sufficient detail to provide measurements of diameters with the accuracy required to provide robust tests of our hypothesis. However, where we have evidence at very circular large monuments of comparable date, such as the stone circle of the Ring of Brodgar, Orkney (Renfrew, 1979) and the Great Circle at Newgrange, Ireland (O'Kelly 1982) these appear to have similar diameters to the ditch at Stonehenge and may therefore conform to the same measurement standard.

Thus we infer that this measure could have been part of a prehistoric cosmological understanding, connected with circular monument building, that accompanied the changes that accompanied the widespread adoption of Grooved Ware pottery and had social currency throughout the British Isles and Ireland from c.3000 BC (Bradley 1984). The use of the measure in the earlier part of this period may indicate that it became less widely used later on. As time passed, the circularity seen in other henges and stone circles was crucial to emulate, but not the measure. Therefore, we might see future research separating bank and ditch measures from those of concentric circles of both timber and stone, that may suggest regional differentiation in the uptake or persistence of this measure. 
A further consideration is that it is inherently unlikely that chalk would present a durable material for repeated use as a measure, and the drums would be expected to show signs of wear if that were the case. Though the Lavant Drum is slightly waisted, no striations were visible on the surface. In studies of the British Neolithic, the argument that chalk was a substance used to create full-sized and miniature replicas of primary artefacts made from other materials such as stone axes (Montague, in Cleal et al. 1995, 403) has now been documented and demonstrated more widely with new research (Teather 2017, 307). Therefore, it is possible that the Folkton and Lavant Drums are chalk representations of lidded, hollowed wooden vessels, a material that would be sufficiently robust and hardwearing to sustain repeated usage as a standard of measurement.

A measuring rope could have been wrapped around the outside of the drum to check its length prior to use. As natural and somewhat elastic organic fibrous materials, ropes or sinew would have been subject to variations in length caused by fluctuations in temperature and /or humidity, and wooden measuring cylinders of known dimensional properties could have served to check rope lengths. Wood has a low coefficient of thermal expansion and only expands or contracts slightly (typically less than 1\%) in the radial direction in response to changes in humidity (Dinwoodie 2000).

Since wood rarely survives in archaeological contexts from this period, particularly on and around the chalklands, discovery of such an artefact in wood would require exceptional luck. Where wood is preserved in prehistoric contexts, such as at the recent excavations at the Late Bronze Age site of Must Farm, Cambridgeshire, there is a wealth of artefactual evidence that displays its common use in the past to manufacture boats, buckets, wheels, a miniature box and platters (Knight et al. 2016). Large assemblages of wooden artefacts have also been recovered from Neolithic lake-dwellings of the Alpine region (e.g. Menotti 2007).

In addition to their variation in size, the Folkton drums are distinguished from each other by their patterns of surface decoration. As we have hypothesised that the Folkton drums had a functional purpose in defining a measurement standard in the Neolithic, their motifs may have a purpose other than simple decoration. Folkton III has two separate motifs of concentric circles on its top, and Folkton II has four. Four rotations of Folkton II would produce a measurement of 5 long feet and two rotations of Folkton III, 2 long feet. The largest Drum, Folkton I, has one set of 5 concentric circles centrally placed on its top. Seven 
rotations of that Drum would produce 10 long feet, so it is not clear whether the number of rings have a simple relationship to usage as a standard of measurement. It is possible that that the design of rings, and/or the number of rings depicted on the 'lids' of the drums may encode instructions concerning rotation, though further work should be undertaken on this element of the surface decoration in order to ascertain it possible meaning.

\section{Conclusion}

Monuments were built throughout the two thousand years of the British Neolithic and across Britain. Thom's $(1955 ; 1967)$ efforts to identify a standard measure, and its multiples and subdivisions, that could encompass the dimensions of all monuments is flawed and has not been accepted by most scholars, including the present authors. However, we have presented evidence from the dimensions of monuments and artefacts which implies that at least one measure was in use during the Neolithic. Building on previous work that identified a standard measure in the construction of Stonehenge and the Southern Circle at Durrington Walls, we have suggested that this measure is incorporated in the dimensions of the chalk drums from Lavant and Folkton. It has been argued that the Folkton and Lavant Drums were symbolic representations of measuring cylinders that could have served both as containers and as standards for checking the lengths of measuring cords. These cords could then have been used for accurately laying out the architecture of Stonehenge and other monuments in the British Neolithic.

For almost 150 years the Folkton Drums have been viewed as beautiful yet unfathomable artefacts. A new understanding that their size and design elements may, in fact, have applications to monument construction has intriguing implications for our knowledge of Neolithic society. Since the Folkton Drums were included as grave goods for a child burial, does this mean that standard measures were somehow associated with children, or growth, or the human life-cycle including learning and the inter-generational transmission of knowledge? These items were almost certainly prestigious although how, or to what extent they held social power, is unknown. This work opens up the field of material culture studies to exciting new possibilities. While we know that there was a complex embedded cultural system present in Neolithic Britain, we now have a better understanding of how widespread it might have been and how we may better examine it in future research. 


\section{References}

Barnatt, John and Moir, Gordon, 'Stone circles and megalithic mathematics', Proceedings of the Prehistoric Society, 50 (1984), 197-216.

Baxter, Michael, Statistics in archaeology. London: Arnold, 2003.

Bradley, Richard, The Social Foundations of Prehistoric Britain. London: Longman, 1985.

Chamberlain, Andrew and Parker Pearson, Michael, 'Units of measurement in Late Neolithic southern Britain' in Mats Larsson and Michael Parker Pearson (eds) From Stonehenge to the Baltic. Living with cultural diversity in the third millennium BC, Oxford: Archaeopress, 2007, 169-174.

Chippindale, Christopher, Stonehenge complete. London: Thames and Hudson, 1983.

Cleal, Rosamund MJ, Walker, Karen, E and Montague, Rebecca, Stonehenge in its landscape: twentieth century excavations. London: English Heritage, 1995.

Cummings, Vicki, 'The architecture of monuments' in Joshua Pollard (ed.) Prehistoric Britain, Oxford: Blackwell, 2008, 135-159.

Dinwoodie, John M, Timber: its nature and behaviour. London: Taylor and Francis, $2^{\text {nd }}$ edition, 2000.

Freeman, Peter R, 'A Bayesian analysis of the Megalithic Yard', Journal of the Royal Statistical Society A, 139 (1976), 20-55.

Glob, Peter V, The mound people: Danish Bronze Age man preserved. London: Faber, 1974.

Greenwell, William, 'Recent researches in barrows in Yorkshire, Wiltshire, Berkshire, etc', Archaeologia, 52 (1890), 1-72.

Hurcombe, Linda M, Archaeological artefacts as material culture. London: Routledge, 2007.

Jones, Andrew M, Prehistoric materialities, Oxford: Oxford University Press, 2012.

Jones, Andrew M., Cochrane, Andrew, Carter, Chris, Dawson, Ian, Díaz-Guardamino, Marta, Kotoula, Eleni, and Minkin, Louise, 'Digital imaging and prehistoric imagery: a new analysis of the Folkton Drums', Antiquity, 89 (2015) 1083-1095.

Kendall, David G, 'Hunting quanta', Philosophical Transactions of the Royal Society of London A 276 (1974), 231-266.

Kenny, James and Teather, Anne M, 'New insights into the Neolithic chalk drums from Folkton (North Yorkshire) and Lavant (West Sussex)', PAST: The Newsletter of the Prehistoric Society 83 (2016) 5-6. 
Kinnes, Ian A, and Longworth, Ian H, Catalogue of the excavated prehistoric and RomanoBritish material in the Greenwell Collection. London: British Museum, 1985.

Knight, Mark, Harris, Susanna and Appleby, Grahame, 'Must Farm: An extraordinary tale of the everyday', Current Archaeology, 319 (2016).

Lloyd, David R, 'How old are the Platonic Solids?', BSHM Bulletin: Journal of the British Society for the History of Mathematics, 27 (2012), 131-140.

Longworth, Ian H, 'The Folkton drums unpicked', in Rosamund Cleal and Ann MacSween (eds) Grooved ware in Britain and Ireland, Oxford: Oxbow Books, 1999, 83-88.

MacKie, Euan W, Science and society in prehistoric Britain, London: Elek, 1977.

Middleton, Andrew, Young, Jeremy R, and Ambers, Janet, 'The Folkton

Drums: chalk or cheese?' Antiquity 78 (2004), Project Gallery,

http://www.antiquity.ac.uk/projgall/middleton299/

Menotti, Francesco, (ed.) Living on the lake in prehistoric Europe: 150 years of lake-dwelling research, London: Routledge, 2007.

O'Kelly, Michael J., Newgrange: archaeology, art and legend, London: Thames and Hudson, 1982.

Parker Pearson, Michael, Pollard, Joshua, Richards, Colin, Thomas, Julian, Tilley, Christopher, Welham, Kate, and Albarella, Umberto, 'Materializing Stonehenge: the Stonehenge Riverside Project and new discoveries, Journal of Material Culture 11 (2008), 227-261.

Porteous, Hugh L, 'Megalithic yard or megalithic myth?', Journal for the History of Astronomy 4 (1973) 22-24.

Raftery, Barry, 'A wooden trackway of Iron Age date in Ireland', Antiquity, 60 (1986), 50-53.

Renfrew, Colin, Investigations in Orkney, London: Society of Antiquaries, 1979.

Robb, John, 'Prehistoric art in Europe: a deep-time social history', American Antiquity, 80 (2015), 635-654.

Ruggles, Clive, 'Astronomy in prehistoric Britain and Ireland', New Haven: Yale University Press, 1999.

Sievers, Susanne, 'Auf dem Weg zur Stadt: die keltische Oppida Zivilisation', in Manfred Nawroth, Rüdiger von Schnurbein, Rainer-Maria Weiss and Mathias Will (eds) Menschenzeiten - raume: Archäologie in Deutschland, Berlin: Staatliche Museen zu Berlin, 2002, 203209.

Teather, Anne M, 'More than 'Other Stone' - new methods to analyse prehistoric chalk artefacts' in Ruth Shaffrey (ed.) Written in stone. Papers on the function, form, and 
provenancing of prehistoric stone objects in memory of Fiona Roe. St Andrews: Highfield Press, 2017, 303-321.

Thom, Aleaxander, 'A statistical examination of the megalithic sites of Britain, Journal of the Royal Statistical Society A, 118 (1955), 275-291.

Thom, Alexander, Megalithic sites in Britain. Oxford: Clarendon Press, 1967.

Thom, Alexander, Thom, Archibald Stevenson and Thom, Alexander Strang, 'Stonehenge', . Journal for the History of Astronomy 5 (1974), 71-90.

Thomas, Julian S, Time, culture and identity: an interpretive archaeology, London: Routledge, 1996.

Wainwright, Geoffrey J with Longworth, Ian H, Durrington Walls: excavations 1966-1968. London: Society of Antiquaries, 1971.

\section{Figure Captions}

Figure 1: Illustration of the Folkton Drums (Thomas, 1996, 158)

Figure 2: Plan of Stonehenge (Cleal et al. 1995) overlain by superimposed concentric circles with diameters of successive intervals of 30 long feet. The outermost circuit of the monument is the counterscarp bank with a diameter of 360 long feet, the main bank has a diameter of 300 long feet and the Aubrey Holes circuit has a diameter of 270 long feet. The sarsen circle does not have a diameter corresponding to a multiple of 30 long feet, but it has a midline circumference of exactly 300 long feet with each of the 30 sarsen lintels having a length of 10 long feet.

Figure 3: Plan of the Phase 2A and 2B postholes at the Durrington Walls Southern Circle overlain by superimposed concentric circles with diameters of between 30 and 120 long feet, (after Wainwright with Longworth, 1971, Fig. 12, supplemented by additional data from Parker Pearson et al., 2008, Fig. 8).

Figure 4: The maximum diameters and maximum heights of the Folkton and Lavant drums. 


\title{
The Chalk Drums from Folkton and Lavant: Measuring Devices from the Time of Stonehenge
}

\author{
Anne Teather ${ }^{1}$, Andrew Chamberlain ${ }^{1}$, Mike Parker Pearson ${ }^{2}$ \\ 1. School of Earth and Environmental Sciences, University of Manchester, Manchester, M13 \\ 9PT, U.K. (anne.teather@manchester.ac.uk, andrew.chamberlain@manchester.ac.uk) \\ 2. Institute of Archaeology, UCL, 31-34 Gordon Square, London, WC1H OPY, U.K. \\ (m.parker-pearson@ucl.ac.uk)
}

\section{Acknowledgments}

Our thanks to Julian Thomas for permission to use Figure 1. 


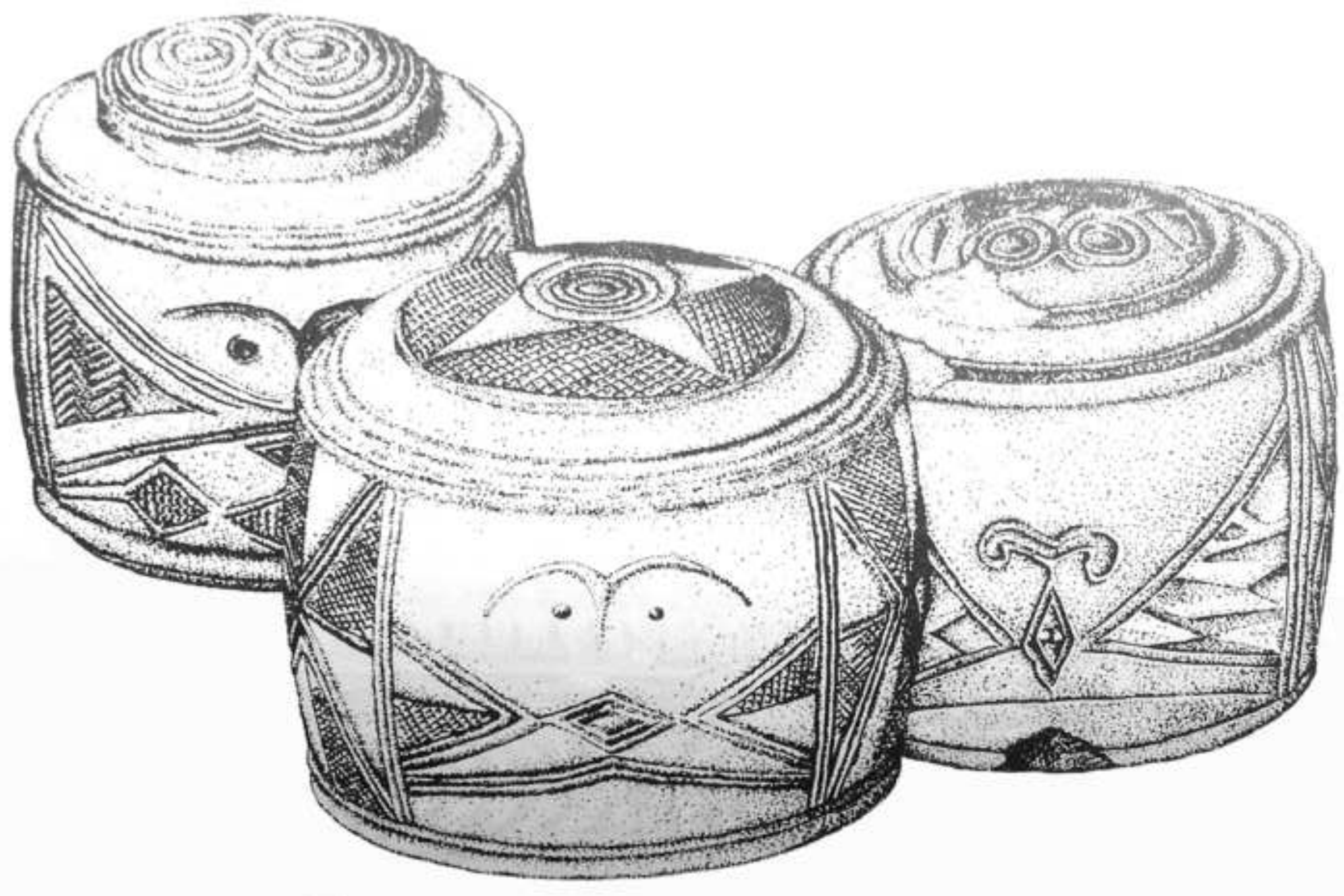




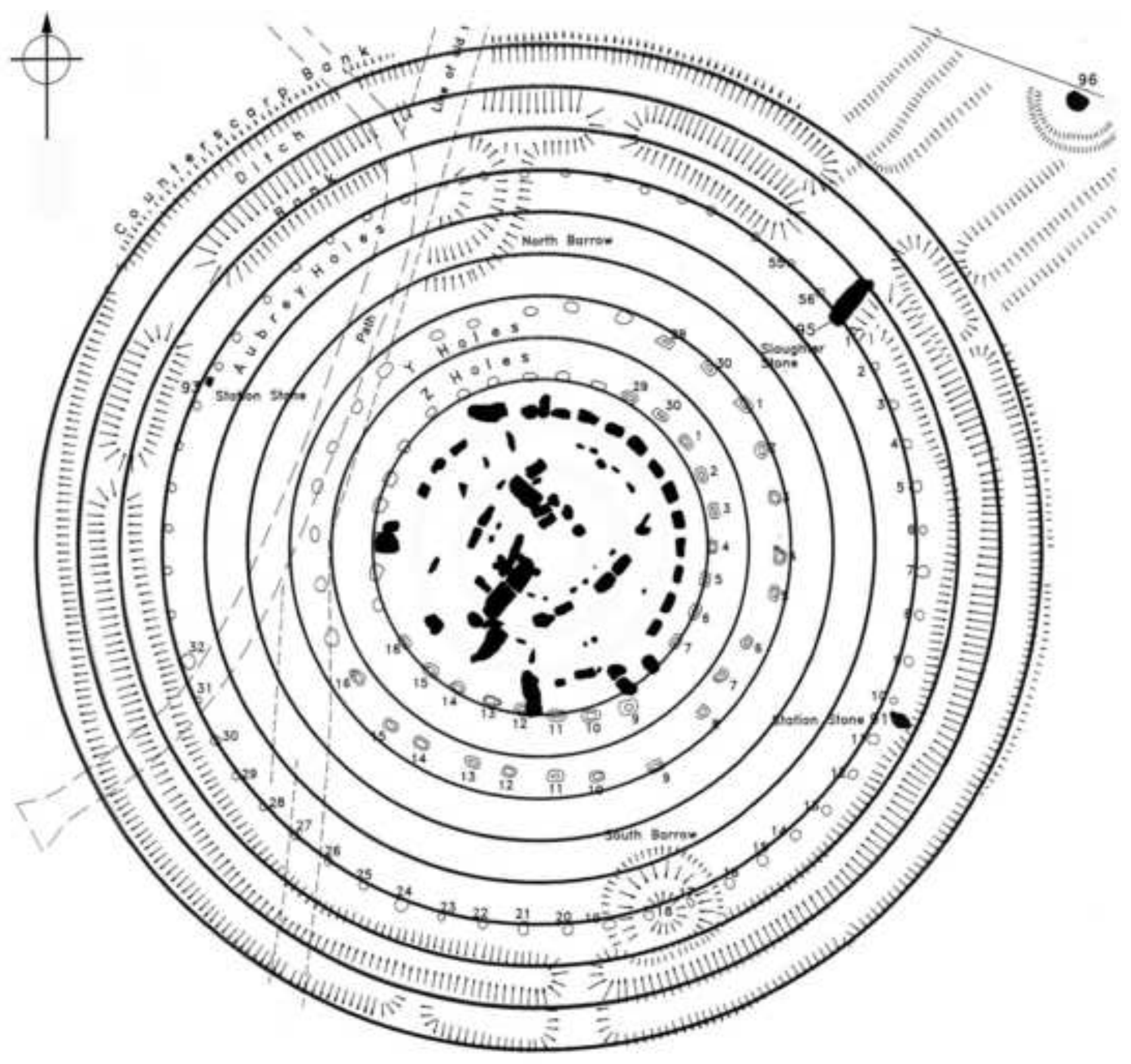




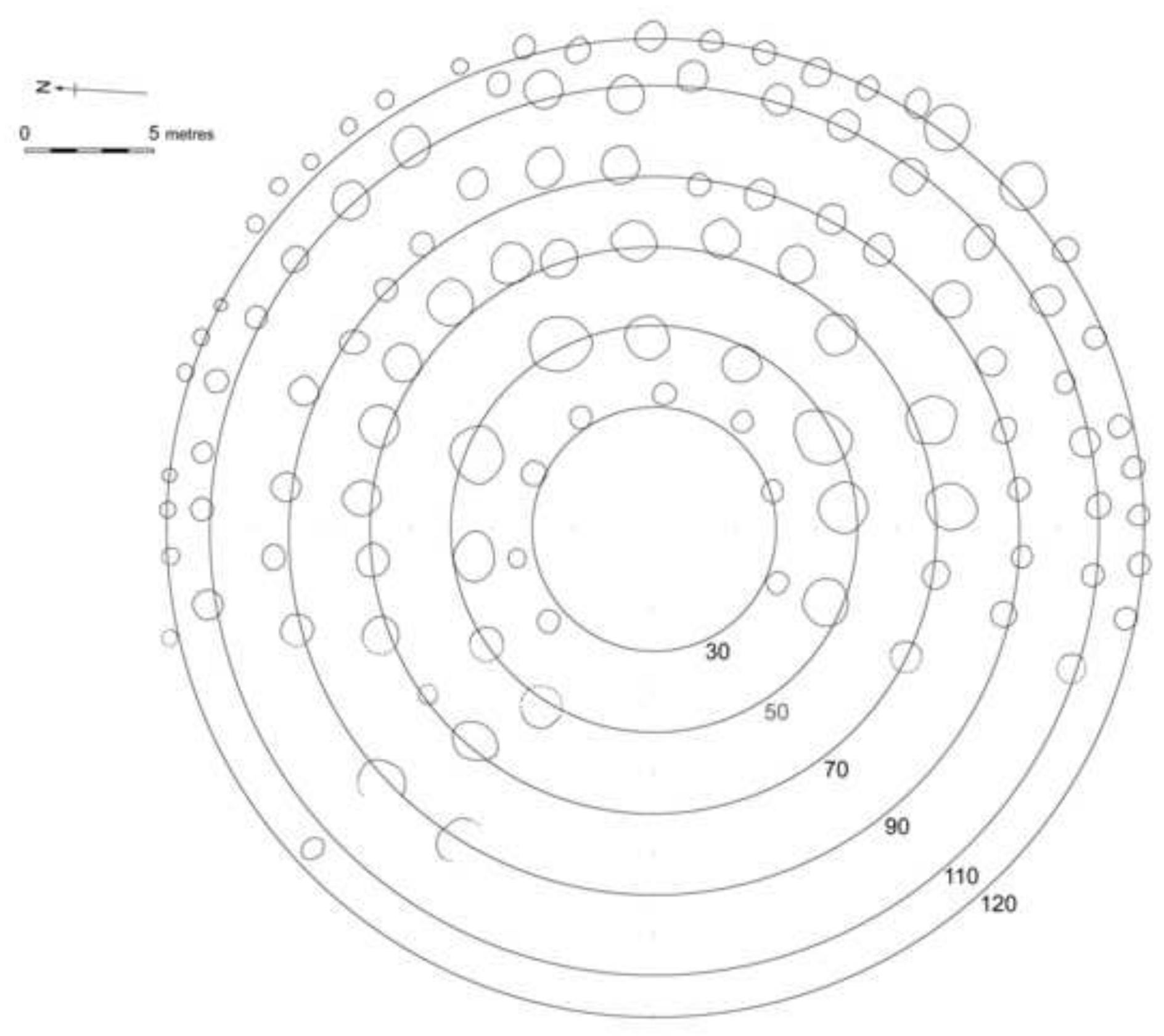




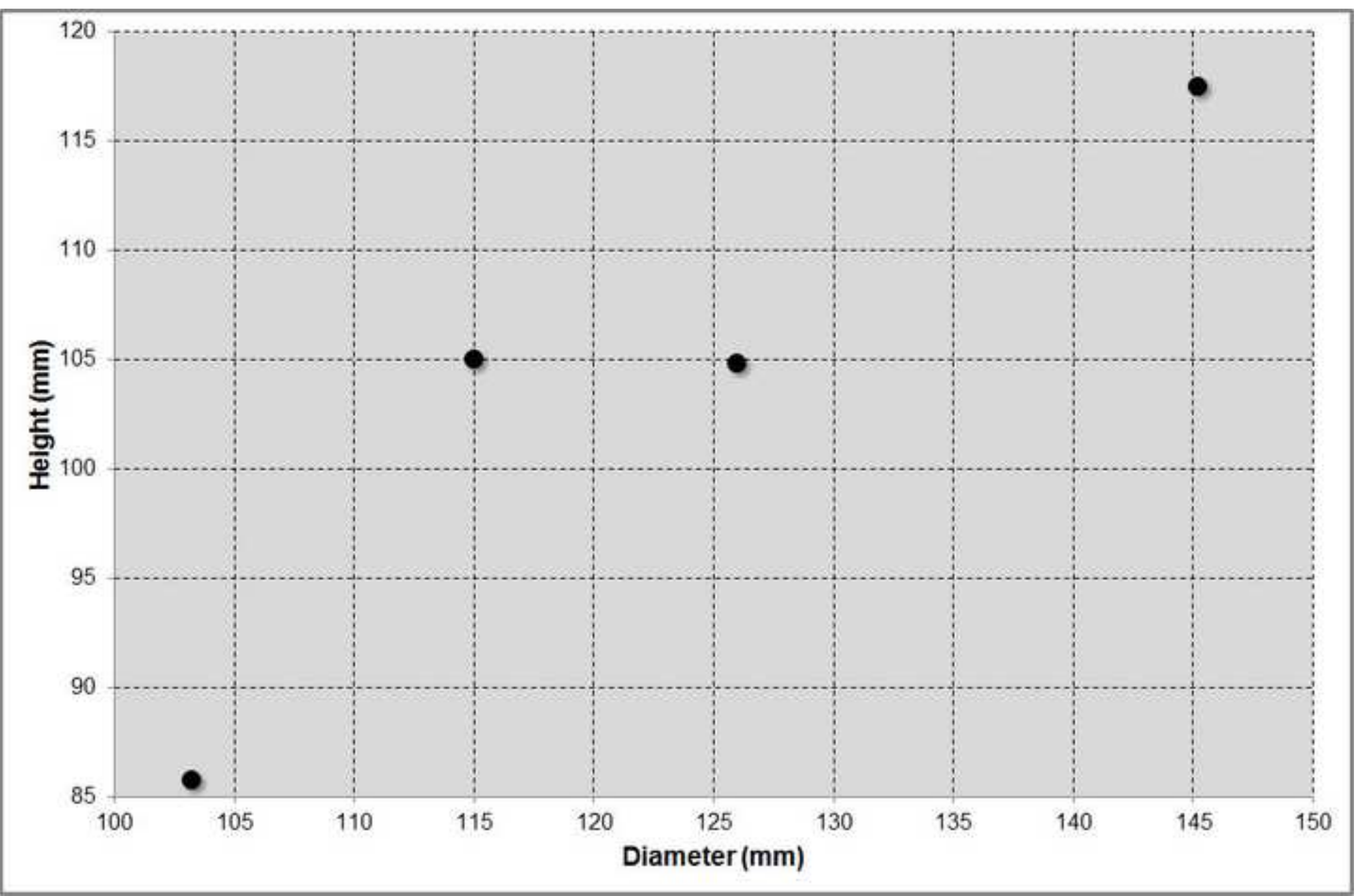




\section{Tables}

\begin{tabular}{|l|c|c|c|c|}
\hline Drum & Diameter $(\mathbf{m m})$ & $\begin{array}{c}\text { Circumference } \\
\text { ( } \mathbf{m m})\end{array}$ & $\begin{array}{c}\text { Circumference } \\
\text { (long feet) }\end{array}$ & Subdiv. of 10 long feet \\
\hline Folkton III & 103.2 & 324.2 & 1.0073 & 9.9 \\
\hline Lavant & 115.0 & 361.3 & 1.1225 & 8.9 \\
\hline Folkton II & 126.0 & 395.8 & 1.2298 & 7.1 \\
\hline Folkton I & 145.2 & 456.2 & 1.4172 & \\
\hline
\end{tabular}

Table 1: Measured maximum diameters and circumferences of the Folkton and Lavant drums (circumferences calculated as diameters multiplied by $\pi$ ). The circumferences have the properties that they approximate to successive integer subdivisions $(1 / 10,1 / 9,1 / 8$ and $1 / 7)$ of a standard length of 10 long feet. 